\title{
Perceived Stress, Positive Resources and Their Interactions as Possible Related Factors for Depressive Symptoms
}

\author{
Hyu Jung Huh', Kyung Hee Kim², Hee-Kyung Lee², \\ Bo Ram Jeong ${ }^{3}$, Ji Hyun Hwang ${ }^{3}$, and Jeong-Ho Chae ${ }^{1,3 凶}$ \\ 1'Department of Psychiatry, The Catholic University of Korea College of Medicine, Seoul, Republic of Korea \\ 2Department of Psychology, The Catholic University of Korea College of Social Science, Bucheon, Republic of Korea \\ ${ }^{3}$ Catholic Emotion Research Laboratory, Catholic Biomedical Industrial Institute, Seoul, Republic of Korea
}

\begin{abstract}
Objective The present study aimed to explore how the patterns of interaction between stress and positive resources differ according to the severity of depression and which resources play the most important role among the various positive resources.

Methods The study included 1,806 people who had visited a health screening center for a mental health check-up to evaluate the levels of perceived stress, positive resources, and depressive symptoms. The participants were divided into a depressive group ( $\mathrm{n}=1,642$, mean age 50.60, female 68\%) and a non-depressive group ( $n=164$, mean age 48.42 , female $66.6 \%$ ). We conducted hierarchical regression analyses and simple slope analyses to examine the interaction between perceived stress and positive resources.

Results The interaction between perceived stress and optimism was significantly associated with depression in non-depressive groups. In depressive groups, the interactions between five types of positive resources (optimism, purpose in life, self-control, social support and care) and perceived stress were all significantly related to depression.

Conclusion Interventions that promote optimism can be helpful for preventing inevitable stress from leading to depression. A deficiency in positive resources may be a factor in aggravating depression in stressful situations for people reporting moderate to severe depressive symptoms.

Psychiatry Investig 2021;18(1):59-68
\end{abstract}

Key Words Positive resource, Optimism, Stress, Depression.

\section{INTRODUCTION}

Stress is an inevitable life experience that develops when an individual fails to cope with the external physiological and cognitive distress of daily life. ${ }^{1,2}$ Perceived stress is defined as how an individual understands the amount of stress he or she is exposed to in a period of time. ${ }^{3}$ It is related to a feeling of uncertainty and instability about life and depends on the confidence in one's ability to handle difficulties. Numerous studies have reported that stressful events precede the onset of depressive episodes and have established a link between stress exposure and depressive symptoms. ${ }^{4-6}$ Models of the stress-

Received: June 3, 2020 Revised: September 28, 2020

Accepted: October 20, 2020

$\triangle$ Correspondence: Jeong-Ho Chae, MD, PhD

Department of Psychiatry, Seoul St. Mary's Hospital, The Catholic University of Korea College of Medicine, 222 Banpo-daero, Seocho-gu, Seoul 06591, Republic of Korea

Tel: +82-2-2258-6083, Fax: +82-2-2258-3870, E-mail: alberto@catholic.ac.kr (ac) This is an Open Access article distributed under the terms of the Creative Commons Attribution Non-Commercial License (https://creativecommons.org/licenses/bync/4.0) which permits unrestricted non-commercial use, distribution, and reproduction in any medium, provided the original work is properly cited. depression relationship emphasize the importance of how stressors are perceived and handled. ${ }^{7}$ According to a cognitive model, a person's interpretations of stressors can create negative self-referential beliefs and schemas that may bias his or her information processing once activated. ${ }^{89}$ Accordingly, some cognitive appraisals of stressors are particularly likely to facilitate the development of depression. ${ }^{8}$ In this context, maladaptive coping or cognitive styles are related to greater distress, while more positive and sociable personal resources are associated with a more favorable psychological well-being..$^{10}$ Therefore, identifying protective or buffering factors as well as vulnerable factors in the stress-depression relationship is necessary to develop depression prevention strategies.

Among several protective factors, personal and social resources may alleviate the negative effects of stress and depression. ${ }^{11}$ Resources refer to people's ability to complete daily activities alone or to seek help from others when they are unable to carry out tasks independently. Personal resources are the ability to remain independent while completing daily tasks, even in potentially disadvantageous situations. ${ }^{12,13}$ Personal re- 
sources include cognitive and emotional components as well as a behavioral component and efforts to promote an individual's positivity and well-being. ${ }^{14}$ In the cognitive domain, positive resources include not only how positively a person evaluates oneself but also the ability to think about oneself and the value of the world that can lead that person's life in a desirable direction. From an emotional perspective, a positive emotion regulation strategy that can cope with stressful situations is ideal. The overall ability to engage in self-management and control, including exercise, may be a behavioral element of positive resources. ${ }^{15}$ Social resources include the ability to seek help from others when unable to deal with life by oneself and to ask for help from professionals or family/ friends. ${ }^{16,17}$ It includes the care of others as well as social support from others. Both personal and social resources are of great significance to health promotion and psychological wellbeing. ${ }^{18,19}$

Regarding the relationship between resources and depression, studies have been performed across a number of populations, including community-living older adults, adolescents, pregnant women, nurses, medical students, and patients with breast cancer, diabetes mellitus, and stroke. ${ }^{13,20-25}$ In these studies, individuals' resources have been negatively correlated with depression. Stress was also negatively correlated with resourcefulness. ${ }^{11}$ Individuals with more resources may therefore be more likely to effectively reduce the harmful effects caused by stressful events, which may contribute to a lower perceived level of stress. As suggested by previous studies, perceived stress may also contribute to depression. In addition, individuals with more resources are more capable of effectively using problem-solving abilities, regulating negative thoughts and emotions, and therefore reporting lower levels of depression.

It has been proven that individual resources play a buffer role in the relationship between stress and depression, but there are still many things to be elucidated for these results to have more useful clinical implications. In particular, it is important for the prevention and treatment strategies of depression in the future to clarify how the pattern of the buffering role of positive resources varies according to the severity of depression and which positive resources play the most important role among the various positive resources. The buffering role of positive resources can vary depending on the severity of depression. Many previous studies have suggested that emotion regulation and coping strategies, including resilience, may differ between people with moderate to severe depressive symptoms and those with mild or asymptomatic complaints. ${ }^{26,27}$ Based on these findings and depending on the severity of the depression, there may also be differences in the aspects of the buffer effect of positive resources; identifying these differences will be very important in developing a strategy to prevent the onset, recurrence, and aggravation of depression against inevitable stressors.

The buffering effect of an individual's resourcefulness on the relationship between perceived stress and depression has been verified in various populations, which specific resource plays a key role in the stress-depression link is still unclear. Numerous previous studies have explored various types of individual resources, such as the meaning of life, adaptive coping, and social support. However, to our knowledge, no previous study has compared the buffering effect size of various positive resources with the relationship between stress and depression.

The present study aimed to compare how the interrelationships of positive resources and perceived stress differ in the stress-depressive relationship between the group reporting moderate to severe depression and those who do not complain of mild or any symptoms. Based on previous studies, it is expected that the more severe the depression, the greater the likelihood of experiencing overall emotion regulation difficulty; therefore, various types of positive resources, including self-regulating ability, should have a greater moderating effect. It can be predicted that the positive resources at the individual level along with the degree of social support will play a significant role. In addition, this study will explore not only the difference in the moderating effect of positive resources in the two groups with different levels of depression but also which positive resource has a relatively greater moderating effect on the perceived stress-depression relationship.

\section{METHODS}

\section{Study population}

The medical record of 1,806 people who visited the healthscreening center at Seoul St. Mary's Hospital and underwent a mental health check-up from between March 2015 to May 2017, was included in the present study. This study is based on medical records and conducted research in compliance with the principles of the anonymization process for personal information, and obtained IRB approval for exemption from the consent process. The study protocol was approved by the Institutional Review Board of the Ethics Committee of Seoul St. Mary's Hospital at the Catholic University of Korea (KC16RISI0734).

\section{Measurements}

\section{Socio-demographics and depressive symptom severity}

The participants were asked about their demographic information, including gender, years of formal education, and marital status. We assessed the participants' depressive symptoms using the Korean version of the Patient Heath Question- 
naire-9 (PHQ-9), a multipurpose instrument for screening, diagnosing, monitoring, and measuring the severity of depression. The PHQ-9 consists of 9 items; respondents rate the frequency of the symptoms using a scoring severity index from 0-3. PHQ-9 scores of 5, 10, 15 and represent mild, moderate, and severe depression. ${ }^{28}$ In the present study, the Cronbach's alpha for the PHQ-9 was 0.85 .

\section{Perceived stress}

Stress levels were measured by the Perceived Stress Scale (PSS). The PSS is a self-report instrument that evaluates the level of perceived stress during the previous month. This scale consists of 10 items that ask about the frequency of thoughts and feelings experienced using a Likert-type scale with five response options, between 0 (never) and 4 (very often). The total scale score is the sum of all the items and ranges between 0 and 40; higher scores correspond to higher levels of perceived stress. ${ }^{3}$ In the present sample, the Cronbach alpha for the PSS was 0.79 .

\section{Positive resources}

Positive resources were assessed using the Positive Resources Test (POREST), a self-report questionnaire for assessing an individual's positive resources in a clinical setting. The POREST measures five multi-dimensional positive resources: optimism, purpose/hope, self-control, social support, and care. The test comprises 23 items, and each is rated on a 5-point scale (from $1=$ =not true to $5=$ very true).$^{14}$ In the present sample, the Cronbach alpha for optimism, purpose/hope, selfcontrol, social support, and care were $0.80,0.80,0.67,0.70$, and 0.82 , respectively.

\section{Statistical analysis}

Our main predictive variable was the severity of depressive symptoms. The moderating variables included five types of positive resources, and the dependent variables were the severity of perceived stress. Age, sex, marital status, and years of education were the control variables (Figure 1).

To test for a moderation effect, we performed a hierarchical regression analysis as suggested by Aiken and West (1991). However, when interaction terms are included in a regression model, the effect of multicollinearity may be problematic. Therefore, we produced an interaction term by mean-centering the sum of the scores of the predictive variables (perceived stress) and the moderating variable (positive resources). First, we entered the predictive and moderating variables into the model. Next, we simultaneously included the predictive variables, moderating variable, and interaction terms to examine their effects on the dependent variable. To assess the pattern of the moderation effect, we performed a simple slope analy-

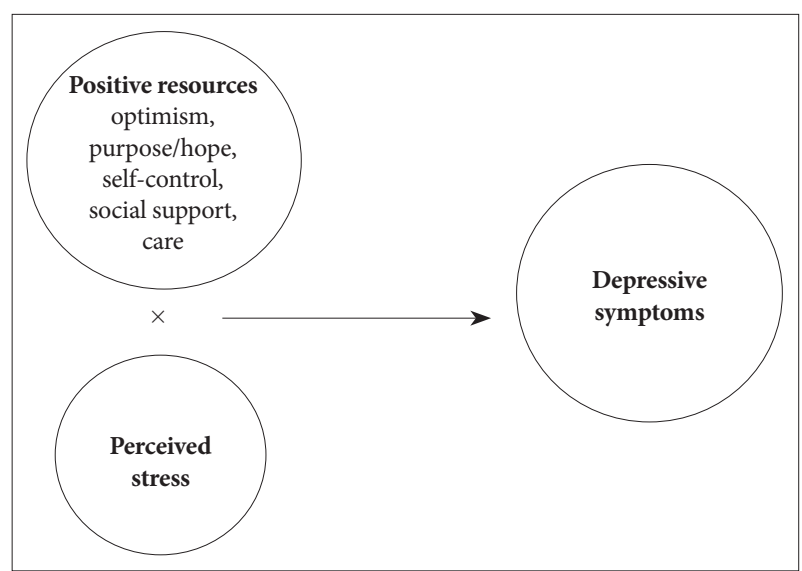

Figure 1. Hypothesized model about interrelation among perceived stress, positive resources and depressive symptoms.

sis. ${ }^{29,30}$ All analyses were performed using the Statistical Package for the Social Sciences (SPSS), version 22.0 (IBM Corp., Armonk, NY, USA).

To identify whether the degree and pattern of moderation effect were different depending on the severity of depressive symptoms, the participants were divided into two groups based on the PHQ-9: a depressive group and a non-depressive group. The depressive group had aPHQ- 9 score $\geq 10$, while the nondepressive group demonstrated a PHQ-9 score $<10 .^{28,31}$ In total, 1,642 participants were categorized into the non-depressive group, and 164 participants were placed in the depressive group.

\section{RESULTS}

\section{Participant characteristics}

Participant demographics and clinical characteristics are presented in Table 1 . The mean participant age was $50( \pm 16.55)$ years, and $68 \%$ were female; $78.9 \%$ participants were married or cohabited. The mean length of education was 15.16 years $( \pm 2.39)$. The average PSS score was $15.64( \pm 7.93)$, and the mean PHQ score was $3.43( \pm 4.24)$. The mean total score on the POREST was 87.01 ( \pm 12.77$)$. Regarding the average subscore on the POREST, the mean scores for optimism, purpose/hope, self-control, social support, and care were 27.02 $( \pm 4.43), 22.41( \pm 4.21), 18.70( \pm 3.31), 11.40( \pm 2.24)$, and 7.49 $( \pm 1.53)$, respectively.

In the non-depressive group, the mean PSS score was 14.70 ( \pm 7.51$)$, and the mean PHQ score was $2.41( \pm 2.54)$. On the POREST, the mean scores for optimism, purpose/hope, selfcontrol, social support, and care were $27.54( \pm 4.03), 22.78$ ( \pm 3.98$), 18.99( \pm 3.14), 11.57( \pm 2.12)$, and $7.51( \pm 1.50)$, respectively (Table 1).

In the depressive group, the mean PSS score was 25.06 ( \pm 5.57$)$, and the mean PHQ score was $13.70( \pm 4.23)$. For the 
POREST subscores, the mean scores for optimism, purpose/ hope, self-control, social support, and care were $21.77( \pm 4.81)$, 18.63 ( \pm 4.59$), 15.79( \pm 3.54), 9.71( \pm 2.61)$, and $7.25( \pm 1.76)$, respectively (Table 1 ).

\section{Bivariate correlations between perceived stress, positive resources, and depressive symptoms}

The correlation matrix for all variables is provided in Table 2. In the non-depressive group, perceived stress was positively correlated with depressive symptoms $(\mathrm{r}=0.55, \mathrm{p}<0.01)$ and negatively correlated with optimism $(r=-0.23, p<0.01)$, purpose/hope $(r=-0.21, p<0.01)$, self-control $(r=-0.20, p<0.01)$, social support $(\mathrm{r}=-0.15, \mathrm{p}<0.01)$, and care $(\mathrm{r}=-0.14, \mathrm{p}<0.01)$. Depressive symptoms were negatively correlated with optimism $(\mathrm{r}=-0.31, \mathrm{p}<0.01)$, purpose/hope $(\mathrm{r}=-0.27, \mathrm{p}<0.01)$, self-control $(\mathrm{r}=-0.26, \mathrm{p}<0.01)$, social support $(\mathrm{r}=-0.20, \mathrm{p}<0.01)$, and care $(\mathrm{r}=-0.11, \mathrm{p}<0.01)$.

In the depressive group, the perceived stress was positively correlated with depressive symptoms $(\mathrm{r}=0.44, \mathrm{p}<0.01)$ and negatively correlated with optimism $(\mathrm{r}=-0.53, \mathrm{p}<0.01)$, purpose/hope $(r=-0.29, p<0.01)$, self-control $(r=-0.32, p<0.01)$, social support $(\mathrm{r}=-0.25, \mathrm{p}<0.01)$, and care $(\mathrm{r}=-0.16, \mathrm{p}<0.05)$. Depressive symptoms were negatively correlated with optimism $(r=-0.55, p<0.01)$, purpose/hope $(r=-0.30, p<0.01)$, selfcontrol $(\mathrm{r}=-0.29, \mathrm{p}<0.01)$, and social support $(\mathrm{r}=-0.31, \mathrm{p}<0.01)$. The correlation between depressive symptoms and care was not significant.

\section{The interaction effect of positive resources and perceived stress on depressive symptoms}

Tables 3 and 4 summarize the results of our analysis of the interaction effect of perceived stress and positive resources on depressive symptoms. The interaction between perceived stress and optimism was significantly associated with depression in non-depressive groups $(\beta=-0.07, \mathrm{p}<0.01)$. To examine the pattern of the interaction, we calculated the dependent

Table 1. Demographic characteristics of participants

\begin{tabular}{|c|c|c|c|c|c|c|c|}
\hline \multirow[b]{2}{*}{ Characteristic } & \multirow{2}{*}{$\begin{array}{c}\text { Mean (SD)/\% } \\
\text { Total group }\end{array}$} & \multirow{2}{*}{$\begin{array}{c}\text { Mean (SD)/\% } \\
\text { Depressive } \\
\text { group }\end{array}$} & \multirow[b]{2}{*}{ Skewness } & \multirow[b]{2}{*}{ Kurtosis } & \multirow{2}{*}{$\begin{array}{c}\text { Mean }(\mathrm{SD}) / \% \\
\begin{array}{c}\text { Non-depressive } \\
\text { group }\end{array}\end{array}$} & \multirow[b]{2}{*}{ Skewness } & \multirow[b]{2}{*}{ Kurtosis } \\
\hline & & & & & & & \\
\hline Age & $50(16.55)$ & $48.32(11.48)$ & & & $50.60(16.96)$ & & \\
\hline Gender (female) & $68 \%$ & $81.7 \%$ & & & $66.6 \%$ & & \\
\hline Educational year & $15.16(2.39)$ & $15.03(2.16)$ & & & $14.46(2.46)$ & & \\
\hline Marital status (married/cohabited) & $78.9 \%$ & $78.7 \%$ & & & $78.9 \%$ & & \\
\hline Perceived stress (PSS) & $15.64(7.93)$ & $25.06(5.57)$ & -0.60 & 0.06 & $14.70(7.51)$ & -0.12 & 0.37 \\
\hline Depression (PHQ-9) & $3.43(4.24)$ & $13.70(4.23)$ & 0.90 & -0.21 & $2.41(2.54)$ & 1.47 & 1.57 \\
\hline Positive resources (POREST_total) & 87.01(12.77) & $73.15(13.35)$ & -0.19 & -0.18 & $88.40(11.85)$ & -0.37 & 1.12 \\
\hline Optimism & $27.02(4.43)$ & $21.77(4.81)$ & -0.29 & -0.03 & $27.54(4.03)$ & -0.52 & 0.37 \\
\hline Purpose \& hope & $22.41(4.21)$ & $18.63(4.59)$ & -0.26 & -0.11 & $22.78(3.98)$ & -0.16 & 0.01 \\
\hline Self-control & $18.70(3.31)$ & $15.79(3.54)$ & -0.20 & -0.27 & $18.99(3.14)$ & -0.15 & 0.08 \\
\hline Social support & $11.40(2.24)$ & $9.71(2.61)$ & -0.41 & 0.05 & $11.57(2.12)$ & -0.29 & -0.26 \\
\hline Care & $7.49(1.53)$ & $7.25(1.76)$ & -0.13 & -0.23 & $7.51(1.50)$ & -0.31 & -0.21 \\
\hline
\end{tabular}

PSS: Perceived Stress Scale, PHQ-9: Patient Health Questionnaire-9, POREST: Posive Resource Test

Table 2. Correlation among perceived stress, positive resources and depression

\begin{tabular}{lccccccc}
\hline & 1 & 2 & 3 & 4 & 5 & 6 & 7 \\
\hline 1. Perceived stress & & $-0.53^{* *}$ & $-0.29^{* *}$ & $-0.32^{* *}$ & $-0.25^{* *}$ & $-0.16^{*}$ & $0.44^{* *}$ \\
2. Optimism & $-0.23^{* *}$ & & $0.63^{* *}$ & $0.50^{* *}$ & $0.49^{* *}$ & $0.24^{* *}$ & $-0.55^{* *}$ \\
3. Purpose \& hope & $-0.21^{* *}$ & $0.64^{* *}$ & & $0.62^{* *}$ & $0.50^{* *}$ & $0.39^{* *}$ & $-0.30^{* *}$ \\
4. Self-control & $-0.20^{* *}$ & $0.58^{* *}$ & $0.65^{* *}$ & & $0.32^{* *}$ & $0.27^{* *}$ & $-0.29^{* *}$ \\
5. Social support & $-0.15^{* *}$ & $0.62^{* *}$ & $0.53^{* *}$ & $0.46^{* *}$ & & $0.26^{* *}$ & $-0.31^{* *}$ \\
6. Care & $-0.14^{* *}$ & $0.33^{* *}$ & $0.41^{* *}$ & $0.34^{* *}$ & $0.38^{* *}$ & -0.09 \\
7. Depression & $0.55^{* *}$ & $-0.31^{* *}$ & $-0.27^{* *}$ & $-0.26^{* *}$ & $-0.20^{* *}$ & $-0.11^{* *}$ & \\
\hline
\end{tabular}

The top of the diagonal is the correlation of the depression group, the bottom of the diagonal is the correlation of the non-depressed group. The mean and standard deviation values in parentheses are the mean and standard deviation of the depressed group. The values outside the parentheses of the mean and standard deviation are the mean and standard deviation of the non-depressed group. ${ }^{*} \mathrm{p}<0.05,{ }^{* *} \mathrm{p}<0.01$ 
Table 3. Interaction effect of positive resources and perceived stress on two dimensions of depression

\begin{tabular}{|c|c|c|c|c|c|c|c|c|c|c|c|c|c|c|}
\hline & \multicolumn{7}{|c|}{ Depressive group } & \multicolumn{7}{|c|}{ Non-depressive group } \\
\hline & \multicolumn{14}{|c|}{ Severity of depressive symptoms } \\
\hline & $\mathrm{B}$ & $\beta$ & $\mathrm{t}$ & $\mathrm{R}^{2}$ & $\Delta \mathrm{R}^{2}$ & $\mathrm{~F}$ & Cohen's $f^{2}$ & $\mathrm{~B}$ & $\beta$ & $\mathrm{t}$ & $\mathrm{R}^{2}$ & $\Delta \mathrm{R}^{2}$ & $\mathrm{~F}$ & Cohen's $f^{2}$ \\
\hline Constant & 13.29 & & $4.81^{* *}$ & & \multirow{4}{*}{0.08} & \multirow{4}{*}{$17.91^{* *}$} & \multirow{4}{*}{0.15} & 3.51 & & $7.20^{* *}$ & & \multirow{4}{*}{0.00} & \multirow{4}{*}{$77.73^{* *}$} & \multirow{4}{*}{0.00} \\
\hline Perceived stress (X) & 0.16 & 0.22 & $2.72^{* *}$ & 0.38 & & & & 0.16 & 0.37 & $14.18^{* *}$ & 0.28 & & & \\
\hline Optimism (Z) & -0.40 & -0.45 & $-5.67^{* *}$ & & & & & -0.14 & -0.21 & $-8.12^{* *}$ & & & & \\
\hline $\mathrm{XZ}$ & -0.04 & -0.30 & $-4.82^{* *}$ & 0.46 & & & & -0.01 & -0.07 & $-2.81^{* *}$ & 0.28 & & & \\
\hline Constant & 13.04 & & $4.35^{* *}$ & \multirow{3}{*}{0.28} & \multirow{4}{*}{0.04} & \multirow{4}{*}{$9.73^{* *}$} & \multirow{4}{*}{0.06} & 3.66 & & $7.43^{* *}$ & & \multirow{4}{*}{0.00} & \multirow{4}{*}{$70.85^{* *}$} & \multirow{4}{*}{-} \\
\hline Perceived stress (X) & 0.31 & 0.41 & $5.45^{* *}$ & & & & & 0.18 & 0.41 & $16.89^{* *}$ & 0.27 & & & \\
\hline Purpose \& hope (Z) & -0.19 & -0.20 & $-2.62^{*}$ & & & & & -0.10 & -0.15 & $-6.11^{* *}$ & & & & \\
\hline $\mathrm{XZ}$ & -0.03 & -0.21 & $-3.08^{* *}$ & 0.32 & & & & 0.00 & -0.02 & -0.71 & 0.27 & & & \\
\hline Constant & 12.46 & & $4.09^{* *}$ & \multirow{3}{*}{0.27} & \multirow{4}{*}{0.07} & \multirow{4}{*}{$10.86^{* *}$} & \multirow{4}{*}{0.12} & 3.70 & & $7.50^{* *}$ & & \multirow{4}{*}{0.00} & \multirow{4}{*}{$70.27^{* *}$} & \multirow{4}{*}{-} \\
\hline Perceived stress (X) & 0.31 & 0.41 & $5.38^{* *}$ & & & & & 0.18 & 0.41 & $16.75^{* *}$ & 0.26 & & & \\
\hline Self-control (Z) & -0.23 & -0.19 & $-2.50^{*}$ & & & & & -0.12 & -0.14 & $-5.78^{* *}$ & & & & \\
\hline $\mathrm{XZ}$ & -0.05 & -0.27 & $-3.98^{* *}$ & 0.34 & & & & 0.00 & -0.03 & -1.14 & 0.26 & & & \\
\hline Constant & 13.76 & & $4.60^{* *}$ & \multirow{3}{*}{0.27} & \multirow{4}{*}{0.04} & \multirow{4}{*}{$9.10^{* *}$} & \multirow{4}{*}{0.06} & 3.83 & & $7.77^{* *}$ & & \multirow{4}{*}{0.00} & \multirow{4}{*}{$67.97^{* *}$} & \multirow{4}{*}{ - } \\
\hline Perceived stress (X) & 0.32 & 0.42 & $5.63^{* *}$ & & & & & 0.19 & 0.43 & $17.44^{* *}$ & 0.26 & & & \\
\hline Social support(Z) & -0.29 & -0.18 & $-2.39^{*}$ & & & & & -0.14 & -0.12 & $-4.75^{* *}$ & & & & \\
\hline $\mathrm{XZ}$ & -0.05 & -0.19 & $-2.72^{* *}$ & 0.31 & & & & 0.00 & 0.01 & 0.34 & 0.26 & & & \\
\hline Constant & 13.97 & & $4.57^{* *}$ & & & & & 4.00 & & $8.07^{* *}$ & & & & \\
\hline Perceived stress (X) & 0.35 & 0.47 & $6.33^{* *}$ & 0.24 & 003 & 7 & 0 & 0.20 & 0.46 & $19.06^{* *}$ & 0.25 & 000 & $k *$ & - \\
\hline Care $(\mathrm{Z})$ & -0.05 & -0.02 & -0.26 & & 0.00 & 1.01 & 0.04 & -0.05 & -0.03 & -1.14 & & 0.00 & 04.02 & - \\
\hline $\mathrm{XZ}$ & -0.06 & -0.16 & $-2.21^{*}$ & 0.27 & & & & 0.00 & -0.02 & -0.65 & 0.25 & & & \\
\hline
\end{tabular}

${ }^{*} \mathrm{p}<0.05,{ }^{* *} \mathrm{p}<0.01$

value according to three different levels of optimism (Mean, Mean+1SD, Mean-1SD) using regression equations (Table 4, Figure 2). The results demonstrated a significant positive relationship between perceived stress and depressive symptoms at all three different levels of optimism (Mean, Mean+1SD, Mean-1SD).

In the depressive group, the interactions between perceived stress and optimism $(\beta=-0.30, \mathrm{p}<0.01) /$ purpose/hope $(\beta=-0.20$, $\mathrm{p}<0.01) /$ self-control $(\beta=-0.27, \mathrm{p}<0.01) /$ social support $(\beta=-0.19$, $\mathrm{p}<0.05) /$ care $(\beta=-0.16, \mathrm{p}<0.05)$ were significant related to the severity of depressive symptoms. A simple slope analysis showed a significantly positive association between perceived stress and depressive symptoms in the group with low (-1SD) and moderate levels of optimism. For the group with a high (+1SD) level of optimism, perceived stress was not significantly associated with depressive symptoms. In addition, our results demonstrated a significant positive relationship between perceived stress and depressive symptoms at all three different levels of purpose/hope, self-control, social support and care (Mean, Mean+1SD, Mean-1SD) (Table 4, Figure 3).

\section{DISCUSSION}

Prior studies suggest that positive resources have a buffering effect on the relationship between perceived stress and depressive symptoms across various populations. However, few studies have investigated which specific positive resource exerts the most influence on the stress-depression link. Furthermore, based on previous studies about the general emotion regulation ability of depression, it is possible that the moderation effect of positive resources appears different between mild and moderate to severe depression. In this context, the present study compared how the interactions of perceived stress and positive resources differ between the group reporting moderate to severe depression and that which complain of mild or no significant symptoms. In addition, we explored which positive resource had a relatively greater interaction effect with perceived stress by calculating and comparing the effect size of various positive resources.

In the present study, the interaction between optimism and perceived stress showed the largest moderation effect size among various positive resources on depressive symptoms. The interaction effect was significant in both the depressive 
Table 4. Simple slope analysis about moderation effect of positive resources in the relationship between perceived stress and depression

\begin{tabular}{|c|c|c|c|c|c|}
\hline & $\mathrm{b}$ & SE & $\mathrm{t}$ & LLCI(b) & ULCI(b) \\
\hline \multicolumn{6}{|c|}{ Non depressive group } \\
\hline \multicolumn{6}{|c|}{ Optimism } \\
\hline$-1 S D$ & 0.18 & 0.01 & 13.26 & 0.16 & 0.21 \\
\hline M & 0.16 & 0.01 & 13.71 & 0.13 & 0.18 \\
\hline$+1 \mathrm{SD}$ & 0.13 & 0.02 & 8.28 & 0.10 & 0.16 \\
\hline \multicolumn{6}{|c|}{ Depressive group } \\
\hline \multicolumn{6}{|c|}{ Optimism } \\
\hline$-1 S D$ & 0.36 & 0.07 & 5.15 & 0.22 & 0.50 \\
\hline M & 0.17 & 0.06 & 2.99 & 0.06 & 0.28 \\
\hline$+1 \mathrm{SD}$ & -0.02 & 0.07 & -0.34 & -0.15 & 0.11 \\
\hline \multicolumn{6}{|c|}{ Purpose \& hope } \\
\hline$-1 \mathrm{SD}$ & 0.44 & 0.07 & 6.23 & 0.30 & 0.58 \\
\hline M & 0.31 & 0.05 & 5.54 & 0.20 & 0.42 \\
\hline$+1 \mathrm{SD}$ & 0.18 & 0.07 & 2.52 & 0.04 & 0.32 \\
\hline \multicolumn{6}{|c|}{ Self-control } \\
\hline$-1 \mathrm{SD}$ & 0.50 & 0.07 & 6.81 & 0.35 & 0.64 \\
\hline M & 0.34 & 0.06 & 6.05 & 0.23 & 0.44 \\
\hline$+1 \mathrm{SD}$ & 0.17 & 0.06 & 2.65 & 0.04 & 0.30 \\
\hline \multicolumn{6}{|c|}{ Social support } \\
\hline$-1 \mathrm{SD}$ & 0.45 & 0.08 & 6.00 & 0.30 & 0.60 \\
\hline $\mathrm{M}$ & 0.33 & 0.06 & 5.85 & 0.22 & 0.44 \\
\hline$+1 \mathrm{SD}$ & 0.20 & 0.07 & 2.78 & 0.06 & 0.34 \\
\hline \multicolumn{6}{|l|}{ Care } \\
\hline$-1 \mathrm{SD}$ & 0.48 & 0.08 & 6.03 & 0.32 & 0.63 \\
\hline M & 0.37 & 0.06 & 6.65 & 0.26 & 0.49 \\
\hline$+1 \mathrm{SD}$ & 0.27 & 0.07 & 4.11 & 0.14 & 0.40 \\
\hline
\end{tabular}

and the non-depressive group. Consistent with previous results, the present finding suggests that optimism is an elastic resource that people use to deal with stressful events. ${ }^{32-34}$ The relatively larger effect size of optimism might be due to its close inter-relationship with other positive resources, including overall emotion regulation ability, coping strategy, and social support. Individuals with high levels of optimism experience less unrealistic wishful thinking, self-criticism, and social withdrawal. ${ }^{35}$ In addition, the optimistic individual is given feedback through emotional channels. Overall, positive emotion can enable individuals to achieve their goals and generate ideas to solve problems more effectively. ${ }^{36}$ This finding is in accordance with the theoretical concept of resilience, which is activated when people are exposed to significantly stressful situations. Low resilience as indicated by a lack of hope, optimism, and problem-solving skills, which are also reported to significantly affect depressive symptoms. ${ }^{37-39}$

The interactions between perceived stress and purpose and hope/self-control/social support/care showed significant association with depressive symptoms, which appeared limited in people reporting moderate to severe depressive symptoms. Purpose and hope refers to how coherent, purposeful, and significant a person feels in his or her life regarding personal growth, meaning/value in life, and spirituality. ${ }^{14}$ Based on the vast literature, purpose and hope can be defined as people's ability to comprehend their life circumstances, their possession of motivating and life-organizing goals, and their feeling that their life is important. ${ }^{40}$ Daily events (including stressors) can be evaluated for their relevance to a person's overall understanding of the purpose of his or her life. ${ }^{8}$ Models of depression emphasize the appraisal of stressors within the context of one's purpose in life to determine whether these stressors will lead to psychological pain. A negative view of the self, the world, and the future, which is known as the negative cognitive triad, has been associated with vulnerability to depression. ${ }^{41}$ Thus, purpose in life and related hope represent a mal- 
leable cognitive emotional framework that is directly accessible to a subjective evaluation based on one's own needs and values. ${ }^{42}$ The pragmatic malleability of the purpose in life framework makes it a particularly promising route through which depression-facilitating cognitions may be resisted or reframed. ${ }^{7}$

Self-control is the ability to manage and care for oneself, which is related to autonomy, self-efficacy, concentration, and exercise. One's self-control ability is a positive resource that involves an adaptive cognitive emotion regulation strategy, such as positive reappraisal, positive refocusing, a refocus on planning, and acceptance. Recent research has suggested

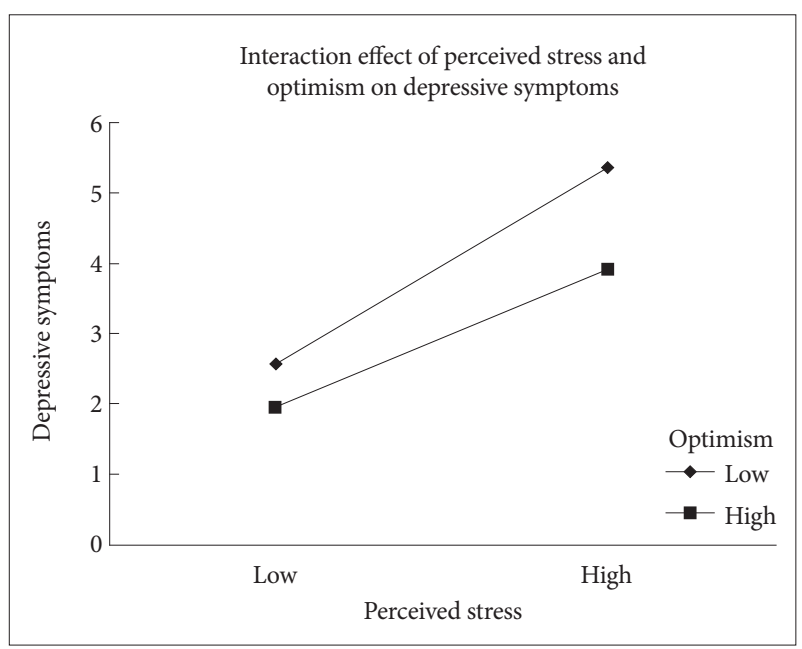

Figure 2. Interaction effect of perceived stress and positive resources on depressive symptoms in non-depressive group. that difficulties in self-regulation after experiencing negative life events may contribute to the risk for the onset of depression. Indeed, evidence indicates that depressed patients exhibit more frequent use of maladaptive strategies when regulating affect and show difficulties effectively implementing adaptive strategies. ${ }^{43}$ Although findings on adaptive emotion regulation strategies are more inconsistent, substantial empirical evidence still remains that depressive patients utilize adaptive emotion-regulation strategies to a lesser extent than healthy controls. ${ }^{44}$ In a former meta-analytic study, self-reported problem solving and reappraisal were negatively associated with symptoms of depression. ${ }^{45}$ A recent review showed that currently depressed individuals reported less frequent use of reappraisal and acceptance of emotions than healthy controls. ${ }^{46}$ Taken together, the lack of positive resources associated with adaptive emotional control skills interacting with stressful events can be a factor in the overall worsening of symptoms for people with moderate to severe depression.

Social support has been one of the most widely studied psychosocial factors in relation to health and disease. ${ }^{47}$ Both preclinical and clinical studies suggest that social support enhances multiple aspects of physical health and plays a key role in reducing stress and depression. ${ }^{48,49}$ These effects of social support appear to be mediated, in part, through effects on other psychosocial factors, such as optimism, and also through effects on multiple neurobiological factors. ${ }^{50}$ Therefore, people with moderate to severe depression may be more vulnerable to stress, especially due to the complex interaction of deficient
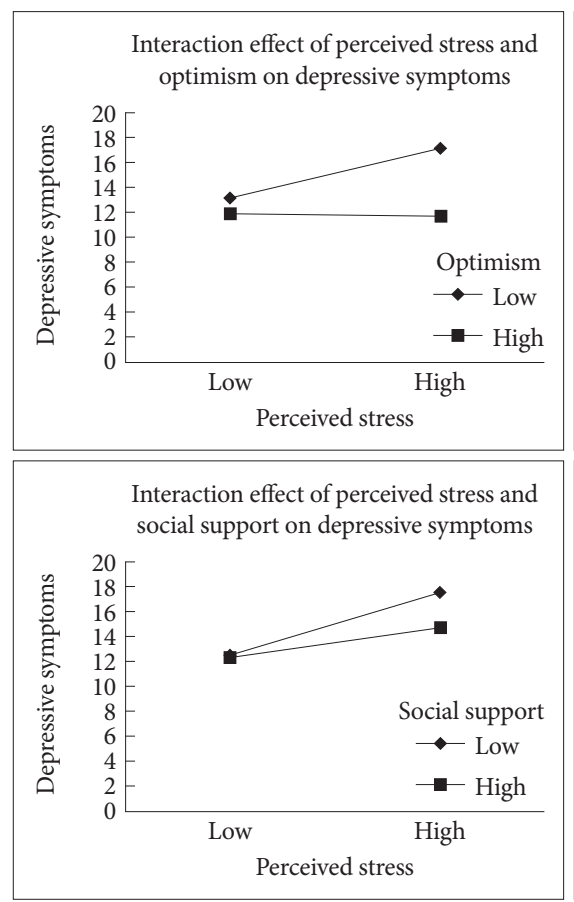
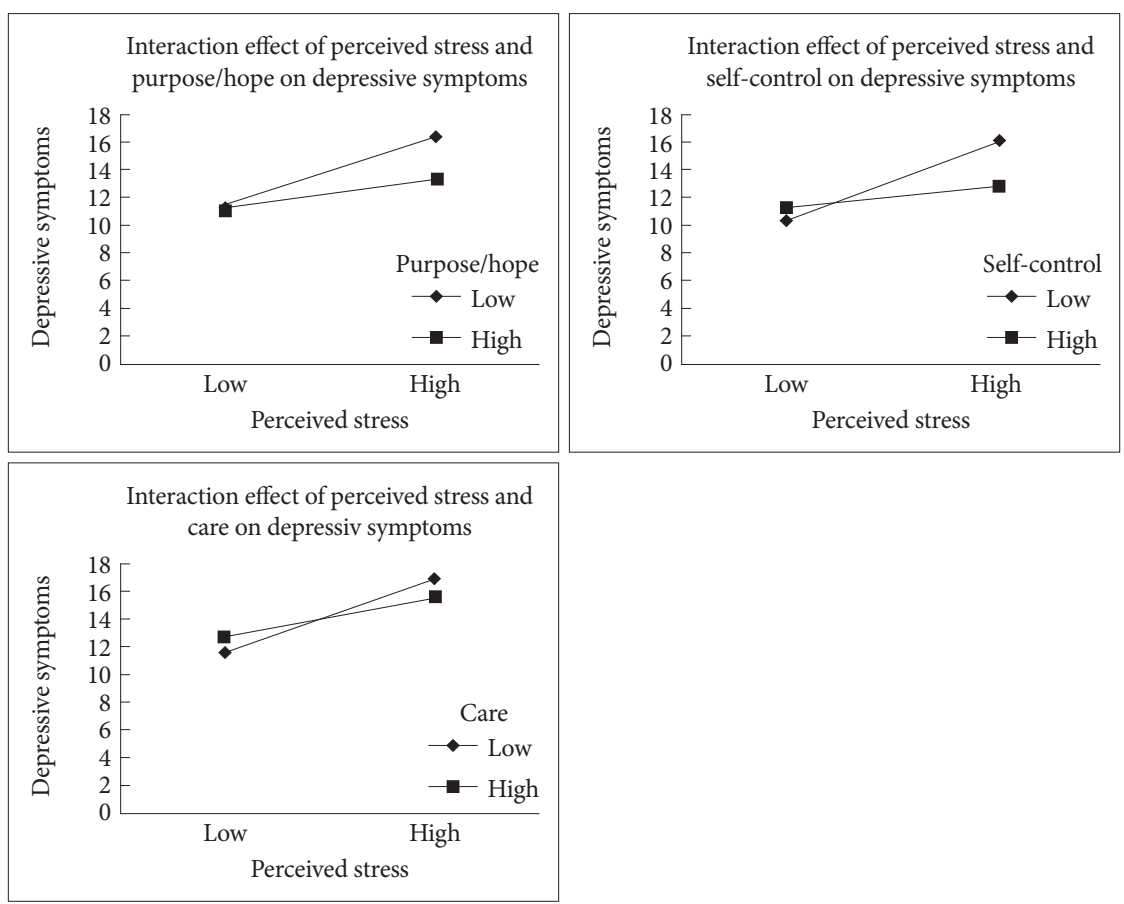

Figure 3. Interaction effect of perceived stress and positive resources on depressive symptoms in depressive group. 
positive resources and social support.

Previous studies reporting a relationship between care-giving behavior and depression showed mixed results. Several previous studies reported that care-giving behavior especially financial support for others was harmful for major depression. ${ }^{51,52}$ On the other hand, other studies showed that caring as a part of resilience against stress helps overcome depression. ${ }^{47,53}$ Some people find meaning by contributing to society, providing for their families, or striving for worthy workrelated goals. ${ }^{54}$ Therefore, care-giving behavior and related meaning in a stressful situation may provide the strength to cope with and tolerate depression. The present results showed that the interaction between care-giving behavior and stress is not simple. Based on previous studies, care-giving behavior may be a vulnerable factor for depression in low stress situations, but the possibility of contributing to resilience in stressful situations should be also considered. For elucidating complex interactions in more detail, a longitudinal study is needed to explore how the modulating effect of care-giving behavior changes after the time point of stress in the future.

Overall, in the present study, the moderation effect size of positive resources in the relationship between stress and depression was small and was inferred using the Cohen's $f^{2}$. According to the diathesis-stress model, adverse experiences have a particular depressing effect on vulnerable individuals. ${ }^{55}$ Stressful events trigger the disorder when they acquire a special sense of threat to people with specific sensitivities. ${ }^{56}$ Therefore, at the onset of depression triggered by stress, it is necessary to consider the possibility that an individual's vulnerability has a far greater influence than a protective factor, such as a positive resource. Nevertheless, based on the results of this study, it can be expected that interventions that cultivate positive responses, such as optimism, may provide a significant benefit in keeping stress from leading to a worsening of depression. In addition, when reporting a moderate or higher level of depression, a lack of positive resources can be a factor that contributes to a worsening of depression in stressful situations.

\section{Limitation}

This study had several limitations. First, this was a crosssectional study that concurrently obtained measurements. To establish causal relationships, there is a need for future longitudinal studies that follow the depressive symptoms of people who have experienced recent stressful events. In particular, prospective studies that serially assess perceived stress, positive resources, and depressive symptoms after a recent stressful life event would be informative. Another limitation of this study is that all variables, including positive resources, were assessed by self-reports. It is possible that the mental representations of positive resources were distorted depending on the severity of the depressive symptoms. Severely depressed individuals might have a tendency to devaluate their positive resources. In addition, the present study was based on a database of information collected from people examined at a health screening center, and the unique characteristics of these people may differ from the community and clinical population and therefore could have influenced the overall results. For example, those who pay for time and money and undergo medical check-ups may have a high overall interest in their own health and a high socio-economic level. In this study, we tried to control possible demographic variables, such as age, gender, and education level, but the results should be interpreted with caution considering that the characteristics of the participants likely influenced the study. Further, the relationship between stress, positive resources, and depression is likely to be influenced by a variety of factors, including age, gender, educational level, marital status, as well as other psychiatric symptoms and emotional control factors. In the future, an in-depth study that explores the relationship between various variables related to stress, positive resources, and depression through Bayesian network analysis would be helpful in overcoming the limitations of the present study.

\section{Conclusion}

Among diverse personal and social positive resources, the interaction of optimism and perceived stress showed the greatest association with the depression. In addition, the interactions of self-control/purpose \& hope/social support/care and perceived stress exerted a significant interaction effect on the group reporting moderate to severe depression. The findings of this study suggest that interventions promoting positive resources, such as optimism, can be helpful in protecting inevitable stress from leading to depression. Particularly for people suffering from moderate or severe depressive symptoms, a deficiency in positive resources can aggravate depression in stressful situations.

\section{Acknowledgments}

This work was supported by a grant from the Choi Shin-Hai Neuropsychiatric Research Fund of the Korean Neuropsychiatric Association.

\section{Conflicts of Interest}

The authors have no potential conflicts of interest to disclose.

\section{Author Contributions}

Conceptualization: Hyu Jung Huh, Jeong-Ho Chae. Data curation: Jeon Ho Chae. Formal analysis: Hyu Jung Huh, Kyung Hee Kim, Hee-Kyung Lee. Funding acquisition: Hyu Jung Huh. Investigation: Hyu Jung Huh, Bo Ram Jeong, Ji Hyun Hwang, Jeong-Ho Chae. Project administration: Hyu Jung Huh, Jeong Ho Chae. Resources: Jeong-Ho Chae. Software: Jeong-Ho Chae. Supervi sion: Jeong-Ho Chae. Validation: Jeong-Ho Chae. Visualization: Hyu Jung Huh. Writing-original draft: Hyu Jung Huh. Writing-review \& editing: Bo Ram Jeong, Ji Hyun Hwang, Jeong-Ho Chae. 


\section{ORCID iDs}

Hyu Jung Huh Kyung Hee Kim Hee Kyung Lee Bo Ram Jeong Ji Hyun Hwang Jeong-Ho Chae

https://orcid.org/0000-0001-8050-9189 https://orcid.org/0000-0003-1009-9203 https://orcid.org/0000-0002-6854-8772 https://orcid.org/0000-0002-2399-4883 https://orcid.org/0000-0003-1553-3857 https://orcid.org/0000-0002-6070-9324

\section{REFERENCES}

1. Roohafza H, Feizi A, Afshar H, Mazaheri M, Behnamfar O, Hassanzadeh-Keshteli A, et al. Path analysis of relationship among personality, perceived stress, coping, social support, and psychological outcomes. World J Psychiatry 2016;6:248-256.

2. Suldo SM, Shaunessy E, Hardesty R. Relationships among stress, coping, and mental health in high-achieving high school students. Psychol Sch 2008;45:273-290.

3. Cohen S, Kamarck T, Mermelstein R. A global measure of perceived stress. J Health Soc Behav 1983;24:385-396.

4. Hammen C. Stress and depression. Annu Rev Clin Psychol 2005;1:293319.

5. Monroe SM, Hadjiyannakis K. The Social Environment and Depression: Focusing on Severe Life Stress. In: Gotlib IH, Hammen CL, Editors. Handbook of Depression. New York, NY: The Guilford Press, 2002, p.314-340.

6. Paykel ES. Life events and affective disorders. Acta Psychiatr Scand Suppl 2003;(418):61-66.

7. Dulaney ES, Graupmann V, Grant KE, Adam EK, Chen E. Taking on the stress-depression link: meaning as a resource in adolescence. J Adolesc 2018;65:39-49.

8. Beck AT, Haigh EAP. Advances in cognitive theory and therapy: the generic cognitive model. Annu Rev Clin Psychol 2014;10:1-24.

9. Disner SG, Beevers CG, Haigh EA, Beck AT. Neural mechanisms of the cognitive model of depression. Nat Rev Neurosci 2011;12:467-477.

10. Vollrath M, Torgersen S. Personality types and coping. Pers Individ Dif 2000;29:367-378.

11. Wang SM, Lai CY, Chang YY, Huang CY, Zauszniewski JA, Yu CY. The relationships among work stress, resourcefulness, and depression level in psychiatric nurses. Arch Psychiatr Nurs 2015;29:64-70.

12. Zauszniewski JA, Lekhak N, Yolpant W, Morris DL. Need for resourcefulness training for women caregivers of elders with dementia. Issues Ment Health Nurs 2015;36:1007-1012.

13. Guo L, Zauszniewski JA, Liu Y, Yv S, Zhu Y. Is resourcefulness as a mediator between perceived stress and depression among old Chinese stroke patients? J Affect Disord 2019;253:44-50.

14. Huh HJ, Kim SY, Min JA, Chae JH. Development of the Clinical ShortForm Positive Resources Test. Korean J Str Res 2018;26:77-87.

15. Zauszniewski JA. Self-help and help-seeking behavior patterns in healthy elders. J Holist Nurs 1996;14:223-226.

16. Zauszniewski JA. Learned resourcefulness: a conceptual analysis. Issues Ment Health Nurs 1995;16:13-31.

17. Lai CY, Zauszniewski JA, Tang TC, Hou SY, Su SF, Lai PY. Personal beliefs, learned resourcefulness, and adaptive functioning in depressed adults. J Psychiatr Ment Health Nurs 2014;21:280-287.

18. Chen MC, Palmer MH, Lin SY. Creating a conceptual model for family caregivers of older adults intervention research: a narrative review of learned resourcefulness, resourcefulness, and the transtheoretical model. Geriatr Nurs 2018;39:521-527.

19. Bekhet AK, Zauszniewski JA. The effect of a resourcefulness training intervention on relocation adjustment and adaptive functioning among older adults in retirement communities. Issues Ment Health Nurs 2016; 37:182-189.

20. Bekhet AK, Zauszniewski JA. Resourcefulness, positive cognitions, relocation controllability and relocation adjustment among older people: a cross-sectional study of cultural differences. Int J Older People Nurs
2013;8:244-252.

21. Huang CY, Guo SE. Stress, perceived support, resourcefulness and depressive symptoms in Taiwanese adolescents. J Clin Nurs 2009;18:32713279.

22. Huang CY, Sousa VD, Tu SY, Hwang MY. Depressive symptoms and learned resourcefulness among Taiwanese female adolescents. Arch Psychiatr Nurs 2005;19:133-140.

23. Boonpongmanee C, Zauszniewski JA, Morris DL. Resourcefulness and self-care in pregnant women with HIV. West J Nurs Res 2003;25:75-92.

24. Huang CY, Guo SE, Hung CM, Shih SL, Lee LC, Hung GC, et al. Learned resourcefulness, quality of life, and depressive symptoms for patients with breast cancer. Oncol Nurs Forum 2010;37:E280-287.

25. Huang CY, Perng SJ, Chen HF, Lai CY. The impact of learned resourcefulness on quality of life in type II diabetic patients: a cross-sectional correlational study. J Nurs Res 2008;16:264-274.

26. Min JA, Jung YE, Kim DJ, Yim HW, Kim JJ, Kim TS, et al. Characteristics associated with low resilience in patients with depression and/or anxiety disorders. Qual Life Res 2013;22:231-241.

27. Min JA, Lee CU, Hwang SI, Shin JI, Lee BS, Han SH, et al. The moderation of resilience on the negative effect of pain on depression and post-traumatic growth in individuals with spinal cord injury. Disabil Rehabil 2014;36:1196-1202.

28. Kroenke K, Spitzer RL, Williams JB. The PHQ-9: validity of a brief depression severity measure. J Gen Intern Med 2001;16:606-613.

29. Aiken LS, West SG, Reno RR. Multiple regression: Testing and interpreting interactions: sage; 1991.

30. Cohen J, Cohen P, West SG, Aiken LS. Applied Multiple Regression/ Correlation Analysis for the Behavioral Sciences. New York: Routledge; 2013.

31. SH L, YJ H, JH K, CS H. Finding optimal cut off points of the Korean Version of the Patient Health Questionnaire-9(PHQ-9) for screening depressive disorders. Mood Emot 2014;12:32-36.

32. Ironson G, Balbin E, Stuetzle R, Fletcher MA, O'Cleirigh C, Laurenceau JP, et al. Dispositional optimism and the mechanisms by which it predicts slower disease progression in HIV: proactive behavior, avoidant coping, and depression. Int J Behav Med 2005;12:86-97.

33. Thomas JL, Britt TW, Odle-Dusseau H, Bliese PD. Dispositional optimism buffers combat veterans from the negative effects of warzone stress on mental health symptoms and work impairment. J Clin Psychol 2011;67:866-880.

34. Vollmann M, Scharloo M, Langguth B, Kalkouskaya N, Salewski C. Illness representations as mediators of the relationship between dispositional optimism and depression in patients with chronic tinnitus: a cross-sectional study. Psychol Health 2013;29:81-93.

35. Tyser J, Scott WD, Readdy T, McCrea SM. The role of goal representations, cultural identity, and dispositional optimism in the depressive experiences of American Indian youth from a Northern Plains tribe. J Youth Adolesc 2014;43:329-342.

36. Liu B, Pu J, Hou H. Effect of perceived stress on depression of Chinese "Ant Tribe" and the moderating role of dispositional optimism. J Health Psychol 2016;21:2725-2731.

37. Breton JJ, Labelle R, Berthiaume C, Royer C, St-Georges M, Ricard D, et al. Protective factors against depression and suicidal behaviour in adolescence. Can J Psychiatry 2015;60:S5-S15.

38. Burke TA, Connolly SL, Hamilton JL, Stange JP, Abramson LY, Alloy LB. Cognitive risk and protective factors for suicidal ideation: a two year longitudinal study in adolescence. J Abnorm Child Psychol 2016; 44:1145-1160

39. Horwitz AG, Berona J, Czyz EK, Yeguez CE, King CA. Positive and negative expectations of hopelessness as longitudinal predictors of depression, suicidal ideation, and suicidal behavior in high-risk adolescents. Suicide Life Threat Behav 2017;47:168-176.

40. Martela F, Steger MF. The three meanings of meaning in life: distinguishing coherence, purpose, and significance. J Posit Psychol 2016;11: 531-545. 
41. Beck R, Perkins TS. Cognitive content-specificity for anxiety and depression: A meta-analysis. Cognit Ther Res 2001;25:651-663.

42. Steger MF. Meaning in Life. In: Lopez SJ, Snyder CR, Editors. Oxford Handbook of Positive Psychology. 2nd Ed. New York, NY: Oxford University Press, 2009, p.679-687.

43. Joormann J, Stanton $\mathrm{CH}$. Examining emotion regulation in depression: a review and future directions. Behav Res Ther 2016;86:35-49.

44. Visted E, Vollestad J, Nielsen MB, Schanche E. Emotion regulation in current and remitted depression: a systematic review and meta-analysis. Front Psychol 2018;9:756.

45. Aldao A, Nolen-Hoeksema S, Schweizer S. Emotion-regulation strategies across psychopathology: a meta-analytic review. Clin Psychol Rev 2010;30:217-237.

46. Liu DY, Thompson RJ. Selection and implementation of emotion regulation strategies in major depressive disorder: an integrative review. Clin Psychol Rev 2017;57:183-194.

47. Southwick SM, Vythilingam M, Charney DS. The psychobiology of depression and resilience to stress: implications for prevention and treatment. Annu Rev Clin Psychol 2005;1:255-291.

48. Travis LA, Lyness JM, Shields CG, King DA, Cox C. Social support, depression, and functional disability in older adult primary-care pa- tients. Am J Geriatr Psychiatry 2004;12:265-271.

49. Oxman TE, Hull JG. Social support and treatment response in older depressed primary care patients. J Gerontol B Psychol Sci Soc Sci 2001; 56:P35-P45.

50. Bisschop MI, Kriegsman DM, Beekman AT, Deeg DJ. Chronic diseases and depression: the modifying role of psychosocial resources. Soc Sci Med 2004;59:721-733.

51. Kupferberg A, Bicks L, Hasler G. Social functioning in major depressive disorder. Neurosci Biobehav Rev 2016;69:313-332.

52. Fujiwara T. Is altruistic behavior associated with major depression onset? PLoS One 2009;4:e4557.

53. Schwartz C, Meisenhelder JB, Ma Y, Reed G. Altruistic social interest behaviors are associated with better mental health. Psychosom Med 2003;65:778-785.

54. Anderson NB. Emotional Longevity: What Really Determines How Long You Live: New York, NY: Penguin Press; 2003.

55. Kalamatianos A, Canellopoulos L. A diathesis-stress model conceptualization of depressive symptomatology. Psychiatriki 2019;30:49-57.

56. Blatt SJ. Experiences of Depression: Theoretical, Clinical, and Research Perspectives: Washington, DC: American Psychological Association; 2004. 